\title{
STABILIZATION OF SEXUAL PREFERENCES BY SEXUAL EXPERIENCE IN MALE ZEBRA FINCHES TAENIOPYGIA GUTTATA CASTANOTIS
}

\author{
by \\ HANS-JOACHIM BISCHOF and NICKY CLAYTON $\left.{ }^{1}\right)^{2}$ ) \\ (Lehrstuhl für Verhaltensphysiologie, Universität Bielefeld, \\ Postfach 8640, 4800 Bielefeld 1, Germany)
}

(With 3 Figures)

(Acc. 9-IV-1991)

\section{Introduction}

Sexual imprinting is the process by which a young bird learns the speciesspecific characteristics that enable it to find a conspecific mate when adult. LOREnz (1935) claimed that imprinting is a unique learning process that is restricted to a brief period early in life, the so-called "sensitive phase" (Immelmann \& Suomi, 1981), and that once learnt, this preference is remarkably stable. Subsequent research has shown that imprinting does not occur during a sharply defined time window of fixed duration, with a step-like onset and termination. Rather, the "readiness to learn" begins, and ends, more gradually and varies in both time and duration, as a result of the individual's own experiences (BATESON, 1981). Recent experiments on the development of sexual preferences in male zebra finches (Taeniopygia guttata castanotis) demonstrate that information acquired during the sensitive phase is not always permanent: In young males that have been reared by Bengalese finch (Lonchura striata) fosterparents, isolated at 40 days of age and then housed with a zebra finch female for several months after reaching adulthood ( $>100$ days), the preferences established during early development may be altered (Immelmann et al., 1991; Kruijt \& Meeuwissen, 1991). However, this change in preference, which was not observed in earlier studies

1) Present address: EGI, Dept. Zoology, University of Oxford, Oxford OX1 3PS, United Kingdom.

$\left.{ }^{2}\right)$ Acknowledgements: Our thanks are due to Reinhard LAssek and Edda Geissler for animal caretaking and help with the experiments. 
(ImMELMANN, 1972, 1985), can often be prevented by a relatively short $(2 \times 20 \mathrm{~min})$ exposure to a Bengalese and a zebra finch female directly after isolation. In this case, even after subsequent exposure to a zebra finch female for several months, more than $50 \%$ of the young birds preserve their initial preference for females of the foster species.

During the double-choice tests, in which the young male is simultaneously exposed to a Bengalese and a zebra finch female, all the young birds preferentially courted Bengalese finch females. Therefore, IMMELMANN et al. (1991) and KrUiJT \& MeEuwissen (1991) propose that imprinting is a two-step process: Although information about the parents is learnt during a sensitive period early in life this information has to be tested for its validity during a first courtship encounter. If the female which the young male meets in this first encounter is of the same species as its foster-parents, then the information that was acquired earlier is consolidated, otherwise a new preference can replace the previous one.

However, the experiments of Immelmann et al. (1991) and Kruijt \& Meeuwissen (1991) did not specifically address the question of whether it is the first courtship encounter or whether any subsequent exposure to a female of the foster species is sufficient to consolidate the previously acquired sexual preference for Bengalese finch females. An additional problem is that the young males were exposed to the zebra finch female for much longer than to the Bengalese finch female. In order to control for the order of presentation and to balance the effects of exposure to both females young male zebra finches were housed for seven days with a zebra finch female followed by seven days with a Bengalese finch female or vice versa.

All the birds in the experiments of Immelmann et al. (1991) and Krujt \& Meeuwissen (1991) were raised by Bengalese finch foster-parents. Since work by IMMELMANN \& SUOMI (1981) suggests that some sort of own-species bias would lead to a stronger fixation of preferences if the birds are normally-reared by their own species, we wondered whether normally-reared males would also switch their preferences if they were exposed first to a Bengalese finch female when adult.

Only about half of the foster-reared young males in the experiments mentioned above changed their preferences when exposed to a conspecific female during their first sexual encounter as an adult. It seems likely that behavioural interactions both with the parents and siblings during early development and with the zebra finch and Bengalese finch female during adulthood may influence the outcome of the final sexual preference that each young male develops. Behavioural observations 
were made to investigate the possibility that individual differences in their behavioural interactions might account for the individual variation in sexual preferences.

\section{Method}

Experiment 1.

Fig. 1 illustrates the experimental design. Zebra finches were transferred as eggs from their natural parents and raised either by a zebra finch pair or by a pair of Bengalese finch foster-parents. Young males were isolated at 40 days of age and randomly assigned into the groups. At 100 days of age, the birds of one group were given contact with a zebra finch female for seven days, isolated again for 3 days, and then housed for another 7 days with a Bengalese finch female (Fig. 1, groups 1.2 and 2.1). The other birds were exposed to females of both species in the reverse order (Fig. 1, groups 1.1 and 2.2). Thereafter, all the birds were isolated for one week and then tested three times in a double-choice test with an unfamiliar zebra finch and Bengalese finch female for 20 minutes.

Between tests the birds were isolated for three days. The Bengalese finch females used in the double-choice tests were raised by zebra finch parents and therefore reacted with courtship displays to the zebra finch males, as did the conspecific females.

To measure sexual preferences during the double-choice tests we recorded the number of song phrases directed to the Bengalese finch female and to the zebra finch female and a preference score was calculated by the number of song phrases to the zebra finch female, as a proportion of the total number of song phrases directed to both females. The preference scores range from 0.00 to 1.00: 1.00 indicates an exclusive preference for zebra finch females, 0.00 indicates an exclusive preference for Bengalese finch females, and a score of 0.50 results from a male directing $50 \%$ of his song phrases to each female.
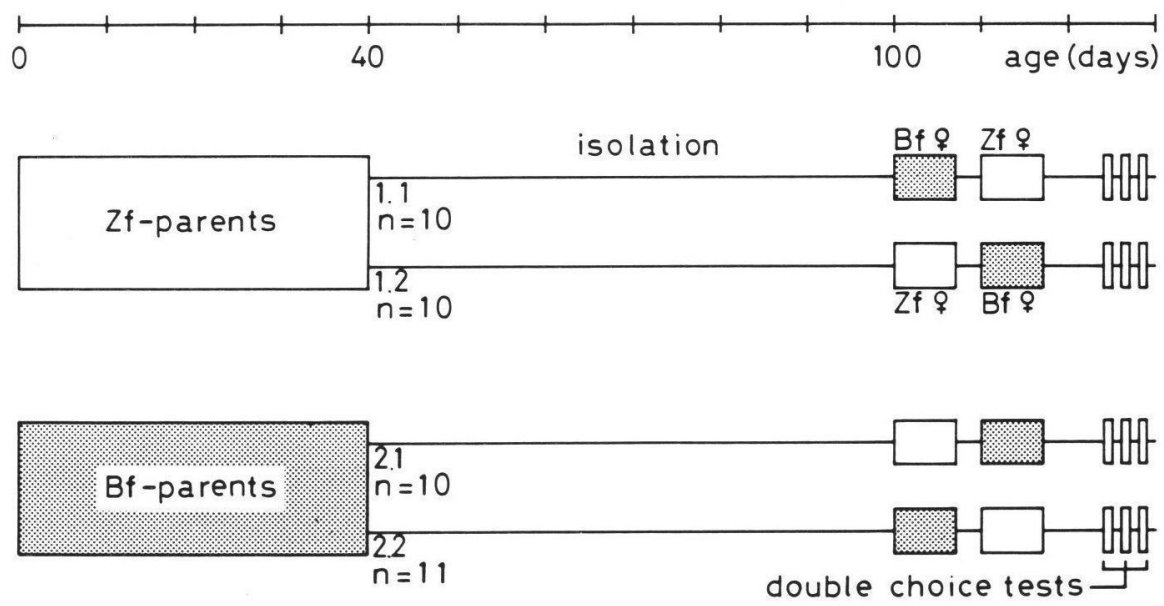

Fig. 1. Outline of the experimental design of the four groups $(1.1,1.2,2.1,2.2)$ in Experiment 1. Zf: Zebra finch. Bf: Bengalese finch. $n$ : Number of males in each group. 
Differences between groups were tested with a $\mathrm{H}$-test and subsequent U-tests (WistatProgram on an Atari Mega St.4). In addition, the preferences of each single bird were determined by a binomial test (SIEGEL, 1976). If this test showed a $95 \%$ probability for one of the two females, the bird was scored to have a preference for this female, otherwise it was scored to have no preference. The results of these calculations are presented because they provide a better indication than the group means of the differences in individual preferences within the groups.

\section{Experiment 2.}

Concerning the question of how the individual preferences of young males emerge, group 2.1 (raised by Bengalese finch parents and exposed first to zebra finch females) was the most interesting one because of the large extent of the variation between individuals in their sexual preferences. We therefore raised a fifth group of zebra finches (Table 1) according to the protocol used for group 2.1 and these birds were observed from day 21 (fledging occurs between day 19 and day 20) until isolation at day 40 for 30 min each morning. In addition, the young males were observed for 1 hour when they were exposed to the zebra finch female after 100 days of isolation, and again for 1 hour when they were put into the cage with a Bengalese finch female. Thereafter, this group underwent three double choice tests with unknown females and one double choice test with the two familiar females using the same protocol as described above.

TABLE 1. Number and sex of the siblings in each clutch in Experiment 2

\begin{tabular}{lcc}
\hline Clutch & No. males & No. females \\
\hline A & 2 & 1 \\
B & 2 & 1 \\
C & 2 & 1 \\
D & 1 & 1 \\
E & 1 & 1 \\
F & 1 & 4 \\
G & 2 & 2 \\
\hline
\end{tabular}

To monitor the behavioural interactions between the young males and all the other birds in the cage all physical encounters were recorded every $30 \mathrm{sec}$ throughout each observation period. For each bird we recorded the following classes of behaviour and to whom they were directed: clumping, preening, aggression (measured as the number of pecks and chases to each individual), eating, singing, attempted and successful copulation, and from day 21 to day 40 , begging and feeding bouts.

\section{Results}

Experiment 1 .

Fig. 2 depicts the mean preference scores obtained for each of the four groups. The first two columns show the results of the zebra finch males 


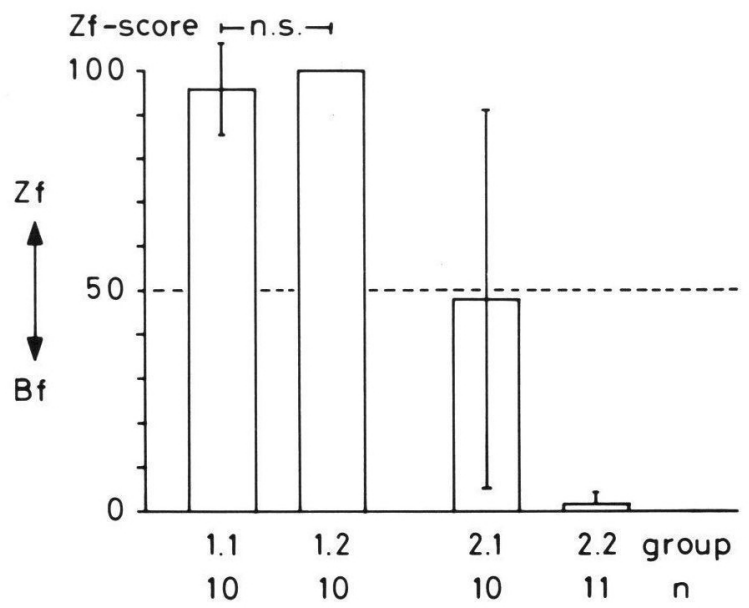

Fig. 2. The mean and standard error of the preference scores of males in each group in Experiment 1 across the three double-choice tests with an unfamiliar zebra finch and an unfamiliar Bengalese finch female. Legend as in Fig. 1.

reared by their own species. All these males developed strong sexual preferences for conspecific females: The birds that were exposed first to Bengalese females as adults (group 1.1) had a mean preference score of $0.96+/-0.10$, and those exposed to zebra finch females first (group 1.2) had a mean score of $1.00+/-0.00$.

The last two columns show the preferences of the birds that were raised by Bengalese finch parents. In these groups, the preferences of the males in the double choice tests depended strongly on the sequence of exposure to the females. If the Bengalese finch-reared birds were first exposed to zebra finch females (group 2.1) the mean preference score was $0.48+1-$ 0.43 . That means the birds as a group had no preference for either species. However, the very large standard deviation already shows that the individual birds behaved very differently. In contrast, if the Bengalese finch-reared birds were first exposed to Bengalese finch females (group 2.2) the preference score was $0.15+/-0.26$. These birds directed their song almost exclusively to the Bengalese finch female.

The $\mathrm{H}$-test demonstrated that there are significant differences between the four groups $\left(\mathrm{H}=27.31, \mathrm{p}<0.0001\right.$; $\mathrm{p}$ estimated by $\chi^{2}$ distribution, $\mathrm{df}=3$ ) and subsequent Mann Whitney U-tests revealed no difference between group 1.1 and $1.2(\mathrm{p}>0.05)$ but all the other groups were significantly different from one another $(\mathrm{p}<0.02)$. 


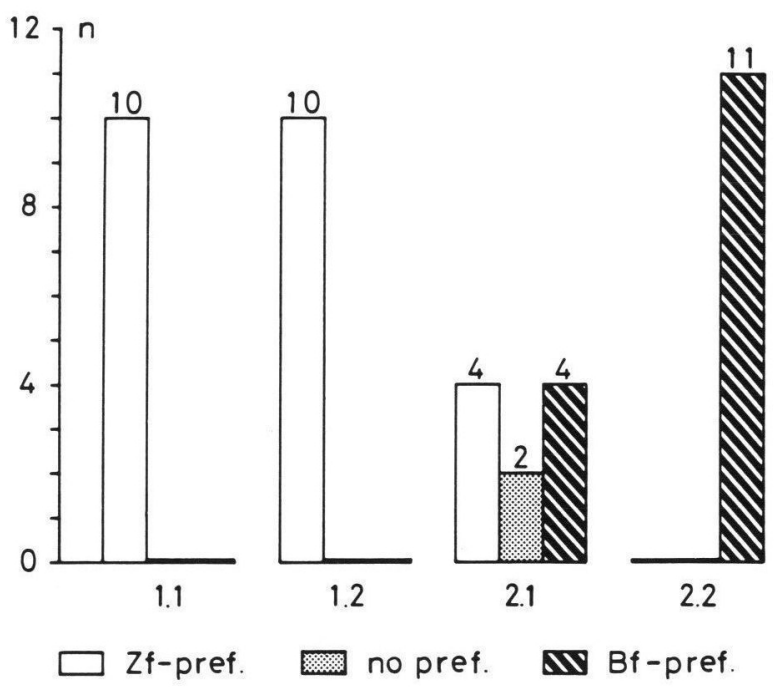

Fig. 3. The number of birds in each group in Experiment 1 that had a preference for zebra finch females (Zf-pref.), for Bengalese finch females (Bf-pref.) or no clear preference (no pref.) for either female in the double-choice tests. The birds' preferences were classified according to a binomial test $(\mathbf{P}<0.05)$. Legend as in Fig. 1.

In contrast to groups $1.1,1.2$ and 2.2 , the standard deviation was quite large in the group of Bengalese finch-reared males which were first exposed to zebra finch females after 100 days isolation. Fig. 3 shows why the standard deviation is so large in this group. It depicts, for each group, the number of birds that directed their song to the zebra finch female or the Bengalese finch female, and the number of birds which did not preferentially sing towards either of the two females. A bird was put into the "no preference"-group if a binomial test did not show a significant preference for either of the test females at the $5 \%$ level. As can be seen from the figure, the birds that were cross-fostered and then first exposed to zebra finches showed large individual differences in their sexual preferences. Four of the birds preferred a zebra finch female, four preferred a Bengalese finch female, and two did not show a preference for either female.

\section{Experiment 2 .}

Of the eleven males, two preferred a zebra finch female, six preferred a Bengalese finch female and two did not show a preference for either 
female in the double-choice tests with the unfamiliar females. The preference scores in the double-choice test with the two familiar females were highly, positively correlated with the mean preference scores across the three tests with the unfamiliar females (Spearman's rank correlation coefficient $=0.90, \mathrm{p}<0.001)$. A Mann-Whitney $\mathrm{U}$ test comparing the mean preference scores to the unfamiliar females showed that these males did not differ significantly $(p>0.05)$ from those in group 2.1 that had also been cross-fostered to Bengalese finches and housed first with a zebra finch and then with a Bengalese finch female.

For each behaviour category we scored the total number of interactions each male had with its zebra finch siblings, as a proportion of the total number of interactions with both siblings and the Bengalese finch fosterparents during the observation period from day 21 to day 40. From Table 1 it can be seen that the males varied in the number of siblings with whom they could interact. To control for this, a second score was calculated: This was a modification of the first score in which the number of interactions with siblings was divided by the total number of siblings present and the number of interactions with the parents was divided by the number of parents present. For both scores, Spearman's rank correlation coefficients gave no significant positive or negative correlations $(p>0.05)$ between any of the behaviour categories and the strength of the sexual preference scores of these males. Given the large individual differences between males in the amount of interaction with siblings and parents, and the fact that different clutches were housed with different numbers of siblings, we compared the young males within each clutch. Of the four clutches in which there was more than one male, a permutation test for paired replicates showed that, in all four cases, the male that begged more to its Bengalese finch foster-parents, and was in turn fed by them more, had a lower sexual preference score $(\mathrm{p}<0.001)$. Comparing brothers within clutches, this means that the one that begs and is fed more by its foster-parents develops a stronger preference for Bengalese finch females.

For each behaviour category we also scored the total number of interactions each male had with the zebra finch female, as a proportion of the total number of interactions with both the zebra finch and the Bengalese finch female during the two seven-day exposure periods. The more song phrases a male directs to the zebra finch female during the first seven-day period, the stronger the sexual preference for zebra finch females in the double-choice tests both with the unfamiliar (Spearman's rank correlation coefficient $=0.65, p<0.05$ ) and with the familiar 
females (Spearman's rank correlation coefficient $=0.67, p<0.05$ ). In contrast, no correlation could be found for any behaviour during the second seven-day period when the young bird was exposed to the bengalese finch female.

\section{Discussion}

The results of the double-choice tests in Experiment 1 show that all the young males that had been raised by zebra finches preferred conspecific females, irrespective of whether they were housed with a zebra finch or with a Bengalese finch female first. In contrast, the preferences of crossfostered males depended on the order of exposure to the two females: those exposed first to a Bengalese finch female preferred Bengalese finch females, whereas of those exposed first to a zebra finch female, some preferred zebra finches, some preferred Bengalese finches and some showed no marked preference for either female.

This difference in sexual preference between the two groups of crossfostered males is in line with the theory proposed by Immelman et al. (1991) and Kruijt \& MeEuwissen (1991), namely the preference for Bengalese finches obtained in early development is not stable until the birds have been able to verify by courting whether the image learnt in early development is adequate as a subject for courtship behaviour. This process of verification may consolidate the stored information and prevent it from further change. If the information cannot be verified during the first courtship encounter, then it can be at least partly replaced by new information from the first sexual partner. This would explain why those males that had been exposed first to a Bengalese finch female all preferred Bengalese finch females in the subsequent double-choice tests whereas only about half of those that had been exposed to the zebra finch female first showed a Bengalese finch-directed sexual preference. The results also indicate that the order in which the young males were exposed to the two females is crucial: $I$ t is the first exposure to a female which consolidates the information rather than any exposure to a female of the same species as the foster-parents.

The fact that the order of exposure to the two females had a significant effect on the sexual preferences of cross-fostered zebra finch males but not on those of normally-raised birds suggests that there is an "ownspecies' bias in the stability of these preferences. However, although all the normally-raised birds preferred zebra finch females in the doublechoice tests, it is interesting to note that those exposed to a zebra finch 
female first exclusively courted conspecific females whereas some of those exposed to a Bengalese finch female first also courted the Bengalese finch females. In the case of the cross-fostered birds there was considerably more individual variation in the sexual preferences of young males that were exposed to the zebra finch female first. This suggests that the males' sexual preferences are more variable when they are first exposed to a female of a different species to that of their parents or foster-parents, even if the female is a conspecific.

The behavioural observations in Experiment 2 go some way towards explaining why the cross-fostered males that were exposed to a zebra finch female first showed so much individual variation in their sexual preferences. The results suggest that behavioural interactions, both with the parents and siblings (day 21 to day 40 ) and during the time in which the males were housed with a female, play an important role in determining the nature of their sexual preferences. TEN CATE et al. (1984) also found that differences in social experience can influence the development of sexual preferences in zebra finch males. They found that normallyraised zebra finches that were then housed with Bengalese finches between day 30 and day 60 were more likely to prefer a Bengalese finch female in subsequent mate choice tests the more they interacted with the Bengalese finches. In particular, clumping and aggression directed towards the young males by the Bengalese finches were found to stimulate a later preference for individuals of the foster-species. The results in Experiment 2 also suggest that certain types of physical encounter may be more effective than others. When comparing brothers within clutches, the one that begs and is fed more by its foster-parents develops a stronger preference for Bengalese finch females. In addition, the more song phrases a male directs to the zebra finch female during the first seven-day period, the stronger the sexual preference for zebra finch females in the double-choice tests.

An intriguing problem is that of assessing the extent to which a young male generalizes from the particular individual(s) it has imprinted on to others of the opposite sex. The strong positive correlation between the sexual preference scores of the males in Experiment 2 for the doublechoice tests with the two familiar females versus those with two unfamiliar females suggests that sexual preferences for zebra finch and/or Bengalese finch females are generalized to all females of that species.

Concerning the interpretation of our results it should be noted that the raising conditions of the birds were rather artificial. The isolation period between day 40 and day 100 may have had two main effects: First, we 
could not find an influence of siblings on the development of sexual preferences, as was suggested previously (Kruijt, 1985). Probably, the influence of siblings increases when the young birds reach independence and more interactions occur between siblings compared with parentsibling encounters. Second, the impact of the "first courtship" experience may have been enhanced by the preceding isolation period. Under normal conditions there may be more than one sexual encounter which consolidates the previously acquired preference; i.e. it may be the effect of a sum of different encounters with females. If these were conspecific siblings, this would explain the "sibling effect" described by KrUiJT and coworkers ( $c f$. KrUiJT, 1985). However, this does not contradict our interpretation of the results presented above. It is likely that the experimental design we used enhances the effect of one sexual encounter and thus makes it visible, but it most probably does not create a different mechanism for the consolidation of the previously acquired preference.

\section{Summary}

Male zebra finches, Taeniopygia guttata castanotis, were normally-raised by zebra finches or were cross-fostered to Bengalese finch, Lonchura striata, foster-parents until 40 days of age. Following isolation until day 100 , half the birds in each group were housed with a zebra finch female for seven days, isolated for three days and then housed with a Bengalese finch female for seven days. The other birds were exposed to females in the reverse order. Subsequent double-choice tests showed that all the normally-raised birds preferred zebra finch females whereas the preferences of cross-fostered males depended on the order of exposure to the two females: those exposed first to a Bengalese finch female preferred Bengalese finch females whereas of those exposed first to a zebra finch female, some preferred zebra finches, some preferred Bengalese finches and some showed no marked preference for either female.

In order to examine the question of why the latter group showed such marked individual variation in their sexual preferences, a further group of males were crossfostered to Bengalese finches and exposed to a zebra finch female and then to a Bengalese finch female and their behaviours were observed from day 21 until day 40 and for the two, seven-day periods with the females. The results show that, when comparing brothers within clutches, the one that begs and is fed more by by its foster-parents develops a stronger preference for Bengalese finch females and that the more song phrases a male directs to the zebra finch female during the first seven-day period, the stronger the sexual preference for zebra finch females in the double-choice tests.

Hence, our results confirm and extend those of ImmelmanN et al. (1991) and Kruju \& Meeuwissen (1991) that sexual imprinting may be a two step process. As a first step, information about the parents is learnt during a sensitive period early in life. In a second step, this information has to be tested for its validity for the selection of a sexual partner during first courtship encounters. It is this second step where the previously stored information is stabilized in memory. Giving conflicting information during the first and the second step, one can show that interactions between the young male and its parents as well as with its first sexual partner influence the final preference it shows in subsequent double choice tests. 


\section{References}

Bateson, P. P. G. (1981). Control of sensitivity to the environment during development. - In: Behavioral development: the Bielefeld interdisciplinary project (K. Immelmann, G. W. Barlow, L. Petrinovich \& M. Main, eds), p. 432-453. Cambridge University Press.

Cate, C. ten, Los, L. \& Schilperoord, L. (1984). The influence of differences in social experience on the development of species recognition in zebra finch males. - Anim. Behav. 32, p. 852-860.

IMmELMANN, K. (1972). The influence of early experience upon the development of social behaviour in estrildine finches. - Proc. XV. Int. Ornith. Congr. The Hague, p. 316-338.

- - (1985). Sexual imprinting in zebra finches-mechanisms and biological significance. - Proc. XVIII Int. Orn. Congr. Moscow 1982, p. 156-172.

- — \& Suomi, S. J. (1981). Sensitive phases in development. - In: Behavioural development: the Bielefeld interdisciplinary project (K. Immelmann, G. W. Barlow, L. Petrinovich \& M. Main, eds), p. 395-431. Cambridge University Press.

- - Pröve, R., Lassek, R. \& Bischof, H.-J. (1991). Influence of adult courtship experience on the development of sexual preferences in zebra finch males. - Anim. Behav. 42, p. 83-90.

Kruijt, J. P. (1985). On the development of social attachment in birds. Neth. J. Zool. 35 , p. $45-62$.

- - \& Meeuwissen, G. B. (1991). Sexual preferences of male zebra finches: Effects of early adult experience. - Anim. Behav. 42, p. 91-102.

Lorenz, K. (1935). Der Kumpan in der Umwelt der Vögel. - J. Ornithol. 83, p. $137-213$

SiEgEL, S. (1976). Nichtparametrische statistische Methoden. - Fachbuchhandlung Psychologie, Verlagsabteilung, Frankfurt/M.

\section{Zusammenfassung}

Männliche Zebrafinken (Taeniopygia guttata castanotis) wurden bis zum 40. Lebenstag von Zebrafinkeneltern oder japanischen Mövchen (Lonchura striata) aufgezogen. Nach Isolation bis zum 100. Lebenstag wurde die Hälfte der Tiere für eine Woche mit einem Zebrafinkenweibchen zusammengesetzt, dann für drei Tage isoliert und anschliessend für weitere sieben Tage mit einem Mövchenweibchen gehalten. Anschliessende Zweifachwahlversuche zeigten, dass alle zebrafinkenaufgezogenen Männchen Weibchen ihrer eigenen Art anbalzten, während bei mövchenaufgezogenen Tieren die Präferenz von der Reihenfolge des Zusammensetzens mit den Weibchen abhing. Wurden diese Männchen zuerst zu Mövchenweibchen gesetzt, bevorzugten sie im Zweifachwahlversuch ebenfalls Mövchenweibchen. Wurden sie zuerst mit Zebrafinkenweibchen gehalten, zeigten sich Präferenzen sowohl für Mövchen als auch für Zebrafinken; einige Tiere zeigten keine Präferenz.

Zur Untersuchung der Ursache für die grossen individuellen Unterschiede in der zuletzt beschriebenen Gruppe zogen wir weitere Männchen unter denselben Bedingungen auf und beobachteten die Interaktionen der Tiere mit ihren Stiefeltern und ihre Reaktionen während der Zeiten mit den Zebrafinken- und Mövchenweibchen. Vergleicht man Paare von Brüdern innerhalb einer Brut, so zeigte das Tier, das mehr bettelte und mehr gefüttert wurde, eine grössere Präferenz für die Stiefelternart. Je mehr Balzgesang ein Männchen gegenüber einem Weibchen in der ersten Expositionsphase zeigte, desto stärker war seine Präferenz für Zebrafinkenweibchen.

Unsere Experimente bestätigen und erweitern die Befunde von Immelmann et al (1991) und Krujt \& Meeuwissen (1991). Danach ist Prägung ein zweiphasiger Prozess, in dem Zebrafinken in einer ersten Phase in früher Jugend Merkmale ihrer Eltern ken- 